\title{
ROLE OF ECHOCARDIOGRAPHY IN DIAGNOSING SUBCLINICAL CASES OF ACUTE RHEUMATIC FEVER AND RHEUMATIC HEART DISEASE IN DEVELOPING COUNTRIES
}

\author{
Shri Krishna Gautam ${ }^{1}$, Jitendra Singh Kushwaha², Anjali Verma ${ }^{3}$, Harshit Khare ${ }^{4}$, Brijesh Kumar ${ }^{5}$, Reena Singh ${ }^{6}$
}

${ }_{1}^{1}$ Associate Professor, Department of Medicine, GSVM Medical College, Kanpur, U. P.

2Professor, Department of Medicine, GSVM Medical College, Kanpur, U. P.

${ }^{3}$ Senior Resident, Department of Medicine, GSVM Medical College, Kanpur, U. P.

4Junior Resident, Department of Medicine, GSVM Medical College, Kanpur, U. P.

${ }_{5}^{5}$ Associate Professor, Department of Medicine, GSVM Medical College, Kanpur, U. P.

${ }^{6}$ Associate Professor, Department of Medicine, GSVM Medical College, Kanpur, U. P.

\section{BACKGROUND}

ABSTRACT

The Acute Rheumatic Fever (ARF) and its sequelae Rheumatic Heart Disease (RHD) continue to be a major cause of cardiac morbidity and mortality in developing countries and diagnosing ARF solely on Jones criteria could lead to under-diagnosis in developing countries. The recent AHA 2015 guidelines highlighted a subgroup of "exceptions to Jones Criteria" for patients with chorea, indolent carditis and previous history of rheumatic fever or "rheumatic heart disease." Such patients may also remain undiagnosed if not properly investigated. Although, the guidelines failed to highlight the role of echocardiography in these subgroups. It is important that suspected population be subjected to echocardiographic screening, as clinical detection of soft murmurs can sometimes be very difficult. Doppler and colour flow mapping is even more sensitive in picking up minor valvular regurgitation. Since in India ARF and RHD continue to be on rampant, we decided to investigate the role of echocardiography in diagnosis of subclinical cases of acute rheumatic fever and rheumatic heart disease in young population of India.

\section{MATERIALS AND METHODS}

A total of 200 patients diagnosed or suspected of RF or RHD attending Outpatient and Inpatient department of LLRH and associated hospitals, GSVM Medical College, Kanpur, were included in the study and subjected to echocardiographic study.

\section{RESULTS}

Out of 200 patients suspected of ARF and RHD, 22 were diagnosed with ARF. Out of 22 ARF patients carditis was diagnosed clinically (on the basis of presence of cardiac murmurs) in 12 of these patients (55\%) and on subjecting patients to 2D Echo Doppler all of these 12 patients had evidence of carditis. In addition, another 6 patients were found to have findings suggestive of carditis on 2D Echo Doppler. It had sensitivity in diagnosing carditis to $82 \%$. Also, the specificity and positive predictive value of 2D Echo Doppler were 100\% each.

\section{CONCLUSION}

Thus, getting a 2D Echo Doppler done in all the patients suspected of acute rheumatic fever or RHD increased our ability to diagnose cases which were otherwise subclinical in their cardiac symptoms.

\section{KEYWORDS}

Rheumatic Heart disease, Rheumatic Fever, Echo, Subclinical RHD.

HOW TO CITE THIS ARTICLE: Gautam SK, Kushwaha JS, Verma A, et al. Role of echocardiography in diagnosing subclinical cases of acute rheumatic fever and rheumatic heart disease in developing countries. J. Evolution Med. Dent. Sci. 2018;7(10):1263-1267, DOI: $10.14260 /$ jemds/2018/288

\section{BACKGROUND}

Acute rheumatic fever and its sequelae rheumatic heart disease is a major problem in children, adolescents and young adults in country like India.

The burden of ARF is distributed unequally around the globe. High-income countries have seen a near eradication of disease. Low-income/ low-resource countries or poorer populations within wealthy countries have seen very little change in ARF incidence. ${ }^{1}$

'Financial or Other Competing Interest': None.

Submission 07-02-2018, Peer Review 23-02-2018,

Acceptance 26-02-2018, Published 05-03-2018.

Corresponding Author:

Dr. Jitendra Singh Kushwaha,

H. No. 7/190-E, Swaroop Nagar,

Kanpur-208002, U. P.

E-mail: drjskushwaha@gmail.com

DOI: $10.14260 /$ jemds $/ 2018 / 288$

\section{(c) (i)}

In fact, as the majority of the world's population lives in high-prevalence regions, $\mathrm{ARF}$ and rheumatic heart disease (RHD; ARF's most devastating complication) remain the leading cause of early cardiovascular morbidity and mortality. Recent data estimates that at least 34.2 million people currently live with RHD with over 340,000 annual deaths. $^{2}$

These considerations, plus evidence that strict adherence to the 1992 Jones criteria resulted in missed ARF diagnosis, 8 led to the development of the Australian ARF diagnostic guidelines. 3,4

The revised Australian guidelines were published in 2012 and expanded on the first edition (2006) to provide clinicians with additional information on preventative action, diagnosis and management of acute rheumatic fever (ARF) and rheumatic heart disease (RHD).

The Australian guidelines were the first to consider highrisk and low-risk populations separately, emphasising high 
sensitivity among those at greatest risk and high specificity for those at lower risk.

It identified high-risk groups as those living in communities with high rates of ARF with incidence > $30 / 100,000$ per year in $5-14$ year olds or RHD all-age prevalence $>2 / 1000$.

Australian guidelines also emphasised that a clinical presentation that falls short by either one major or one minor manifestation, or the absence of streptococcal serology results, but one in which ARF is considered the most likely diagnosis, such cases should be further categorised according to the level of confidence with which the diagnosis is made as highly-suspected ARF or uncertain ARF.

The 2015 Jones criteria revision has embraced this riskstratified approach. 5 Importantly, compared with the Australian guidelines which provide a definition for high risk, the 2015 revision defines low risk as ARF incidence $<2$ per 100,000 school-aged children per year or an all-age prevalence of RHD of $\leq 1$ per 1000 population per year and states that children not clearly from a low-risk ARF population should be considered at moderate-to-high risk (moderate and high are treated equally) and considered under the modified diagnostic pathway. ${ }^{5}$

\begin{tabular}{|c|c|c|}
\hline \multicolumn{3}{|c|}{ Jones criteria for the diagnosis of ARF } \\
\hline & $\begin{array}{l}\text { Low-risk population } \\
\text { ARF incidence } \leq 2 \text { per } 100000 \\
\text { school-aged children or all-age } \\
\text { RHD prevalence of } \leq 1 \text { per } 1000 \\
\text { population year }\end{array}$ & $\begin{array}{l}\text { Moderate/high-risk } \\
\text { population } \\
\text { Children not clearly from } \\
\text { a low-risk population }\end{array}$ \\
\hline \multicolumn{3}{|l|}{ Major criteria } \\
\hline Carditis & Clinical and/or subclinical* & $\begin{array}{l}\text { Clinical and/or } \\
\text { subclinical* }\end{array}$ \\
\hline \multirow[t]{4}{*}{ Arthritis } & Polyarthritis & $\begin{array}{l}\text { Monoarthritis, } \\
\text { polyarthritis and/or } \\
\text { polyarthralgia }\end{array}$ \\
\hline & Chorea & Chorea \\
\hline & Erythema marginatum & Erythema marginatum \\
\hline & Subcutaneous nodules & Subcutaneous nodules \\
\hline \multicolumn{3}{|l|}{ Minor criteria } \\
\hline Carditis & Prolonged PR intervalt & Prolonged PR intervalt \\
\hline Arthralgia & Polyarthralgia & Monoarthralgia \\
\hline Fever & $\geq 38.5^{\circ} \mathrm{C}$ & $\geq 38^{\circ} \mathrm{C}$ \\
\hline $\begin{array}{l}\text { Markers of } \\
\text { inflammation }\end{array}$ & $\begin{array}{l}\text { Peak ESR } \geq 60 \mathrm{~mm} \text { in } 1 \mathrm{~h} \text { and/or } \\
\text { CRP } \geq 3.0 \mathrm{mg} / \mathrm{dL}\end{array}$ & $\begin{array}{l}\text { Peak ESR } \geq 30 \mathrm{~mm} \text { in } 1 \mathrm{~h} \\
\text { and/or CRP } \geq 3.0 \mathrm{mg} / \mathrm{dL}\end{array}$ \\
\hline \multicolumn{3}{|c|}{$\begin{array}{l}\text { Changes compared with the } 1992 \text { revision }{ }^{7} \text { are highlighted in bold. } \\
\text { *Subclinical carditis: Seen only on echocardiography without ausculatory findings. } \\
\text { †Accounting for age variability and only if carditis NOT counted as a major criteria. } \\
\text { ARF, acute rheumatic fever; CRP, C reactive protein; ESR, erythrocyte sedimentation } \\
\text { rate; RHD, theumatic heart disease. }\end{array}$} \\
\hline
\end{tabular}

The criteria recommend that when possible all patients with confirmed or suspected ARF undergo echocardiography to evaluate for carditis with those who are negative on first evaluation undergoing repeated study to assess for evolving cardiac disease. ${ }^{5}$

Diagnosis of subclinical carditis should be made based on specific recommendations for pathological Mitral Regurgitation/ Aortic Regurgitation (MR/AR). Additionally, a normal echocardiogram can rule out a diagnosis of carditis made through clinical auscultation (improving specificity). ${ }^{5}$

Several studies have confirmed that the yield of carditis with valvular regurgitation increased with use of echocardiography in patients with acute rheumatic fever.

Also, echocardiography is of great help in mixed valve lesions to determine the severity of each lesion. Other abnormalities detected on echocardiography in acute carditis include prolapse of the valve, focal nodular thickening of leaflets and pericardial effusion.

Thus, Echocardiography can play a determinant role in the diagnosis of acute rheumatic fever and rheumatic heart disease and to differentiate it from other tropical cardiovascular diseases. 6

While the diagnosis of carditis in acute rheumatic fever traditionally depended on characteristic auscultatory findings, the advent of pulsed and colour Doppler echocardiography provides a method of detecting minor degrees of pathological regurgitation without characteristic clinical signs, thus resulting in an early diagnosis.

\section{Objective}

To validate the usefulness of echocardiography in diagnosing sub-clinical cases of RF/ RHD.

\section{MATERIALS AND METHODS}

A total of 200 patients diagnosed or suspected of RF or RHD attending Outpatient and Inpatient Department of LLRH and associated hospitals, GSVM Medical College, Kanpur, were included in the study and subjected to echocardiographic study and other investigations.

\section{Inclusion Criteria}

Patients suspected of Rheumatic fever or Rheumatic heart disease, based on history with or without symptoms fulfilling revised Jones criteria whether present or past.

\section{Exclusion Criteria}

Patients of Rheumatic fever and Rheumatic heart disease who also had congenital heart disease/ myocarditis/ cardiomyopathies/ degenerative valvular heart disease/ autoimmune aetiology of valvular heart disease.

\section{Study Subjects}

200 patients.

\section{Study Duration}

One year (2014 - 2015).

\section{Study Design}

Observational study.

\section{Investigational Tools and Cut-Off Points}

Echocardiographic Examination.

All patients underwent echocardiographic examination within 24 to 48 hours of establishment of the diagnosis of acute rheumatic fever and before starting anti-inflammatory treatment. A standardised cross-sectional and Doppler echocardiographic examination was performed with multiple orthogonal, parasternal, apical and sub-costal views in all the patients.

For all the 200 patients selected for the study, twodimensionally guided M-mode tracings were obtained, and chamber dimensions and wall thickness were measured with a pair of electronic calipers.

The diameter of the mitral valve annulus was measured at end diastole from the apical four-chamber view by use of an 
inner edge-to-inner edge technique, and three measurements were averaged.

The aortic annulus was measured at end diastole from the parasternal long-axis view by a similar technique. Dilatation of mitral or aortic valve annulus was identified by comparing observed values with reference values for age-matched subjects.

We considered Jones Criteria as a gold standard with which we compared the sensitivity and specificity of Echo screening.

\section{Cardiac Dimensions and Mechanics}

Two-dimensionally guided M-mode tracings were obtained, and chamber dimensions and wall thickness were measured with a pair of electronic calipers.

The diameter of the mitral valve annulus was measured at end diastole from the apical four-chamber view by use of an inner edge-to-inner edge technique, and three measurements were averaged.

The aortic annulus was measured at end diastole from the parasternal long-axis view by a similar technique. Dilatation of mitral or aortic valve annulus was identified by comparing observed values with reference values for age-matched subjects.

\section{Valvular Apparatus}

The structure of the valves and the subvalvular apparatus (in case of mitral valve) and leaflet mobility were carefully evaluated. Valves were examined for the presence of focal or diffuse thickening and leaflet prolapse.

Prolapse of the mitral valve was defined as the systolic displacement of the coaptation point of mitral valve leaflets. Posterior to the plane of the mitral valve annulus into the left atrium is the parasternal long-axis and apical four-chamber views.

Displacement of mitral valve leaflets noted only on the apical four-chamber view was not accepted as prolapse, because this may be caused by a non-planar annulus configuration.

Prolapse of the aortic valve was identified when the tissue or coaptation point of the aortic valve cusp was shifted downward toward the left ventricular outflow tract during diastole in the parasternal long-axis view.

\section{Doppler Colour Flow Imaging}

Doppler colour flow imaging was performed with use of a 5 standard velocity colour map; green colour was added to areas that demonstrated variance in the Doppler signal and thereby served as an index of turbulent flow. The cine loop mode was used for systematic analysis of Doppler flow.

Valvular regurgitation was diagnosed when colour Doppler flow mapping demonstrated reversed flow away from the valve when the valve was closed; signals of very short duration $(<100 \mathrm{~ms}$ ) detected at the time of valve closure were not regarded as true regurgitation.

To differentiate abnormal from physiological regurgitation, the high-velocity turbulent jet had to extend beyond the paravalvular region (more than $1 \mathrm{~cm}$ ) and had to be confirmed by colour-guided pulsed Doppler spectral analysis. The direction of the mitral regurgitant jets was noted in the parasternal long-axis view.
The severity of mitral stenosis was determined by calculation of mitral valve area by computer-assisted planimetry of the mitral orifice (in the short-axis view) in patients with significant regurgitation and by the Doppler pressure half-time method in those without regurgitation.

The mechanisms of mitral or aortic regurgitation were determined on the basis of the presence or absence of leaflet prolapse, annular dilatation, restriction of leaflet mobility, left ventricular dilatation and left ventricular systolic dysfunction.

The Echocardiography Criteria for detection of Acute Rheumatic Carditis were-

- Valvular regurgitation (WHO suggested).

- A regurgitant jet $>1 \mathrm{~cm}$ in length.

- A regurgitant jet in at least two planes.

- A mosaic colour jet with a peak velocity $>2.5 \mathrm{~m} / \mathrm{s}$.

- Jet persists throughout systole (Mitral Valve) and diastole (Aortic Valve).

- Leaflet prolapse.

- Coaptation failure.

- $\quad$ Thickening (> $4 \mathrm{~mm}$ ).

- $\quad$ Reduced mobility.

- Nodules.

- Annular dilatation

- Chordal elongation/ rupture.

- Increased echogenicity of subvalvular apparatus.

- Pericardial effusion.

- Ventricular dilatation and dysfunction (Almost always with Significant Regurgitation).

\section{Statistical Analysis}

Data was compiled and analysed using SPSS 17.0. Categorical data was compared using percentages and Chi-square test was used for analysis. Two-tailed ' $p$ ' values less than 0.05 were considered significant.

\section{RESULTS}

Out of 200 patients included in the study, 22 patients were diagnosed as having acute rheumatic fever in the age group of 5 - 25 yrs. and 88 patients were diagnosed as having RHD, maximum number being in age group of 20 - 30 years with the percentage of $40.90 \%$. Next commonest age group were in the age group of $30-40$ (27.27\%).

\begin{tabular}{|c|c|c|}
\hline Age & No. of Pts. & Percentage \\
\hline $5-10$ yrs. & 2 & $2.27 \%$ \\
\hline $10-20$ yrs. & 20 & $22.72 \%$ \\
\hline $20-30$ yrs. & 36 & $40.90 \%$ \\
\hline $30-40$ yrs. & 24 & $27.27 \%$ \\
\hline $40-50$ yrs. & 4 & $4.54 \%$ \\
\hline $50-60$ yrs. & 2 & $2.27 \%$ \\
\hline \multicolumn{2}{|c|}{ Table 1. Age Distribution of Patients with RHD }
\end{tabular}

Among 22 patients of ARF, polyarthritis was the commonest presentation among the major manifestations. It was present in $18(81.81 \%)$ patients, next common manifestation was carditis. It was present in 12 (54.54\%) patients and chorea present in 1 (4.5\%) patients. 


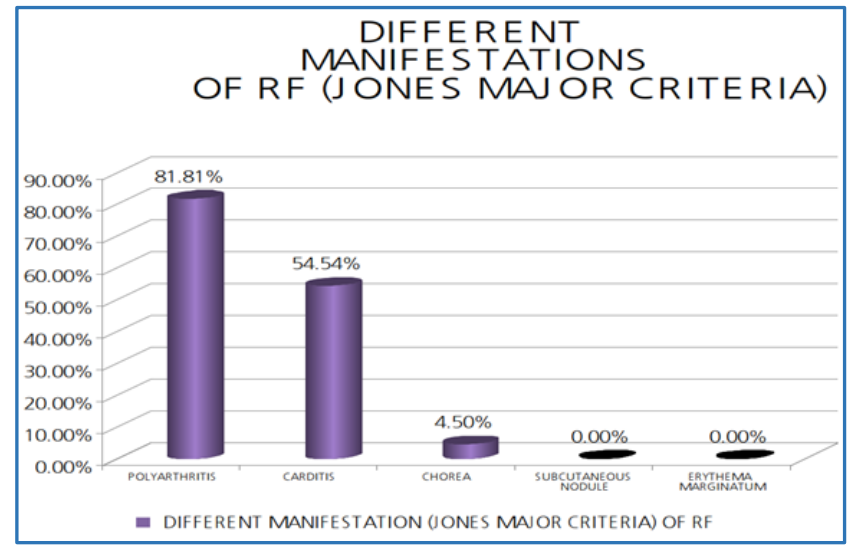

\begin{tabular}{|c|c|c|}
\hline Echocardiographic Findings & No. of Pts. & Percentage \\
\hline Carditis & 18 & $81.8 \%$ \\
\hline Cong. Heart Disease & 4 & $18.18 \%$ \\
\hline \multicolumn{3}{|c|}{ Table 2. 2D-Echo Findings in Suspected Acute } \\
Rheumatic Fever Patients \\
\hline
\end{tabular}

Among 22 patients diagnosed as ARF using 2D echocardiography, 18 (81.81\%) patients showed carditis and small ventricular septal defect were detected in 4 (18.18\%) patients.

\begin{tabular}{|c|c|c|}
\hline Minor Criteria & No. of Pts. & Percentage \\
\hline ASO titre raised & 18 & $81 \%$ \\
\hline Arthralgia & 14 & $63.63 \%$ \\
\hline Fever & 16 & $72.72 \%$ \\
\hline PR prolongation & 4 & $18.18 \%$ \\
\hline Throat culture & 2 & $9.09 \%$ \\
\hline Table & Distribution & of Minor
\end{tabular}

Table 3. Distribution of Minor Criteria in Patients with ARF

Among minor criteria $18(81.81 \%)$ patients presented with raised ASO titre, 16 (72.72\%) patients presented with fever, (2\%) patients presented with arthralgia, 4 (18.18\%) patients presented with prolonged PR and 2 (9.09\%) patients presented with positive throat culture.

\begin{tabular}{|c|c|c|c|c|}
\hline & & \multicolumn{3}{|c|}{$\begin{array}{l}\text { 2D Echocardiography and } \\
\text { Doppler-Detected Carditis }\end{array}$} \\
\hline & & Present & Absent & Total \\
\hline \multirow{3}{*}{$\begin{array}{l}\text { Pts. with } \\
\text { Acute } \\
\text { Rheumatic } \\
\text { Fever }\end{array}$} & Yes & 18 & 4 & 32 \\
\hline & No & 0 & 178 & 178 \\
\hline & Total & 18 & 182 & 200 \\
\hline
\end{tabular}

Sensitivity of 2D echocardiography-detected carditis= $\mathrm{TP} /(\mathrm{TP}+\mathrm{FN})=18 /(18+4)=82 \%$

Specificity of 2D echocardiography-detected carditis= $\mathrm{TN} /(\mathrm{TN}+\mathrm{FP}) \mathrm{r}=178 /(178+0)=100 \%$

Positive Predictive Value $=\mathrm{TP} /(\mathrm{TP}+\mathrm{FP})=18 /(18+0)$ $=100 \%$

Negative Predictive Value $=\mathrm{TN} /(\mathrm{TN}+\mathrm{FN})=178 /(178+4)$ $=97.3 \%$

Here, we found that sensitivity of detection of carditis by clinical examination is $54.54 \%$, whereas it is $82 \%$ by using $2 \mathrm{D}$ echocardiography and Doppler.

\begin{tabular}{|c|c|c|}
\hline Clinical Findings & Number of Patients & Percentage \\
\hline Auscultation & 40 & $20 \%$ \\
\hline ECG & 11 & $5.5 \%$ \\
\hline \multicolumn{2}{|c|}{ Table 5. Clinical Findings in Patients with Valvular } \\
Lesions by Auscultation and ECG \\
\hline
\end{tabular}

Out of 200 patients examined, only $20 \%$ patient had findings on auscultation and $5.5 \%$ had ECG changes suggestive of valvular lesions.

\begin{tabular}{|c|c|c|}
\hline $\begin{array}{c}\text { Valvular Lesions } \\
\text { in RHD }\end{array}$ & $\begin{array}{c}\text { Clinically } \\
\text { Detected }\end{array}$ & $\begin{array}{c}\text { Echocardiographically } \\
\text { Detected }\end{array}$ \\
\hline MR with MS & 22 & 40 \\
\hline Pure MR & 7 & 12 \\
\hline Pure MS & 12 & 20 \\
\hline $\begin{array}{c}\text { Multivalvular } \\
\text { involvement }\end{array}$ & 10 & 16 \\
\hline Total No. of Pts. & $\mathbf{5 1}$ & $\mathbf{8 8}$ \\
\hline Percentage & $25.5 \%$ & $44 \%$ \\
\hline \multicolumn{2}{|c|}{ Table 6. Diagnosing RHD Patients by Clinical } \\
and 2D-Echo Method
\end{tabular}

Clinically, only 51 (25.5\%) patients were diagnosed as different type of valvular lesions against which 88 (44\%) patients were diagnosed as different types of valvular lesions which shows the efficacy of echocardiography in diagnosis of RHD.

\section{DISCUSSION}

As shown in previous studies on RHD patients, max. number of patients were diagnosed in the age group of $20-30 \mathrm{yrs}$. in our study.

Among patients of ARF diagnosed by Jones criteria, while polyarthritis was the commonest presentation, carditis as a major criterion was present only in $54.54 \%$ patients. Also, out of the total patients examined, only $20 \%$ had auscultatory findings and only $5.5 \%$ had ECG findings.

Thus, while Carditis was diagnosed clinically (on the basis of presence of cardiac murmurs) in 12 patients (55\%). On subjecting patients to 2D Echo and Doppler, all of these 12 patients had evidence of carditis. In addition, another 6 patients were found to have findings suggestive of carditis on 2D Echo Doppler. It had sensitivity in diagnosing carditis to $82 \%$. Also, the specificity and positive predictive value of $2 \mathrm{D}$ Echo Doppler were $100 \%$ each.

In our study, clinically only $51(25.5 \%)$ patients were diagnosed as different type of valvular lesions by auscultation and ECG against which 96 (48\%) patients were diagnosed by echocardiography as different types of valvular lesions which shows the efficacy of echocardiography in diagnosis of RHD. This has been supported in an earlier study by IB Vijayalakshmi, 7 which showed that diagnosis of different valvular lesions by clinical criteria was about $33 \%$ and by echocardiography it was about $70 \%$.

Among the major Jones criteria Arthritis was seen in 82\% of the patients, carditis was next to arthritis seen in $55 \%$ of patients. Subcutaneous nodule was seen in only one patient. Sydenham's chorea was seen in $1(4.5 \%)$ patient.

Among the Jones minor criteria, the most common finding seen was raised ASO titre which was found in $82 \%$ of the patients. Fever was present in $72 \%$, arthralgia was present in $64 \%$ and PR interval was prolonged in only $19 \%$ of patients. 
In our study it was seen that out of 96 patients diagnosed as RHD, $24 \%$ patients had isolated mitral stenosis. Isolated mitral regurgitation was seen in $12.5 \%$ of the patients. Both mitral stenosis and regurgitation were present in $43.7 \%$ of the patients.

Multivalvular lesions were seen in $16.6 \%$ patients. These findings were similar to those seen in a study conducted in Pakistan, which showed presence of isolated mitral stenosis in 33.98\%, isolated mitral regurgitation in $8 \%$, isolated aortic valve involvement in $1.69 \%$ and mixed lesions in $56.3 \%$ patients (Md. Faheem et al, 2007). ${ }^{8}$

\section{CONCLUSION}

Thus, getting a 2D Echo Doppler done on all the suspected patients of acute rheumatic fever and RHD increased our ability to diagnose the cases of Acute rheumatic fever and Rheumatic heart disease at a stage where they were not only subclinical in their cardiac symptoms but were also having fewer signs, easily missed by examination, on auscultation and had no/ little ECG findings. This becomes important especially in developing countries like India, where the acute rheumatic fever and rheumatic heart disease together share a major portion of cardiac disease related morbidity and mortality. An early implementation of a non-invasive technique such as an echocardiography can be a convenient and cost-effective tool to reducing this burden of disease in our Indian population.

\section{REFERENCES}

[1] Seckeler MD, Hoke TR. The worldwide epidemiology of acute rheumatic fever and rheumatic heart disease. Clin Epidemiol 2011;3:67-84.

[2] GBD 2013 Mortality and Causes of Death Collaborators. Global, regional, and national age-sex specific all-cause and cause-specific mortality for 240 causes of death, 1990-2013: a systematic analysis for the global burden of disease study 2013. Lancet 2015;385(9963):117-71.
[3] National Heart Foundation of Australia (RF/RHD Guidelines Development Working Group) and the Cardiac Society of Australia and New Zealand. Diagnosis and management of acute rheumatic fever and rheumatic heart disease in Australia-an evidence-based review. 2006. http://www.heartfoundation.org.au/ siteCollectionDocuments/Diagnosis-ManagementAcute-Rheumatic-Fever.pdf

[4] RHD Australia (ARF/RHD Writing Group), National Heart Foundation of Australia, Cardiac Society of Australia and New Zealand. The Australian guideline for prevention, diagnosis, and management of acute rheumatic fever and rheumatic heart disease. 2 nd edn. Casuarina, Australia: RHD Australia, 2012.

[5] Gewitz MH, Baltimore RS, Tani LY, et al. Revision of the Jones Criteria for the diagnosis of acute rheumatic fever in the era of Doppler echocardiography: a scientific statement from the American Heart Association. Circulation 2015;131:1806-18.

[6] Saxena A. Diagnosis of rheumatic fever: current status of Jones criteria and role of echocardiography. Indian J Pedlatr 2000;67(4):283-6.

[7] Vijayalakshmi IB, Mithravinda J, Deva AN. The role of echocardiography in diagnosis carditis in the setting of acute rheumatic fever. Cardiol Young 2005;15(6):5838.

[8] Faheem M, Hafizullah M, Gul A, et al. Pattern of valvular lesions in rheumatic heart disease. J Postgrad Med Inst 2007;21(2):99-103. 